\title{
Anti-diabetic effect of pyroglutamic acid in type 2 diabetic Goto-Kakizaki rats and $\mathrm{KK}-A^{y}$ mice
}

\author{
Orie Yoshinari $^{1^{1 *}}$ and Kiharu Igarashi ${ }^{2}$ \\ ${ }^{1}$ Course of the Science of Bioresource, The United Graduate School of Agricultural Science, Iwate University, Morioka, Iwate \\ 020-8550, Japan \\ ${ }^{2}$ Department of Bioresource Engineering, Faculty of Agriculture, Yamagata University, Turuoka, Yamagata 997-8555, \\ Japan \\ (Received 2 September 2010 - Revised 10 January 2011 - Accepted 9 February 2011 - First published online 10 May 2011)
}

\section{Abstract}

With the rapidly increasing prevalence of type 2 diabetes mellitus (T2DM), specific dietary components with anti-diabetic efficacy could be one strategy with therapeutic potential. In the present study, the anti-diabetic effects of an amino acid, pyroglutamic acid (PA), found in vegetables and fruits were investigated in T2DM models using Goto-Kakizaki (GK) rats and KK- $A^{y}$ mice by measuring glucose tolerance and other markers of diabetes. Moreover, the effect of PA on gene expression in GK rats was measured by DNA microarray analysis. Oral glucose tolerance and serum insulin levels were reduced by PA in both animal models. Serum and liver total cholesterol levels were also improved by PA. Expression of genes involved with gluconeogenesis and those involved with its related transcription factor were downregulated by feeding PA. In KK- $A^{y}$ mice, the glucokinase:glucose-6-phosphatase (G6Pase) activity ratio increased. From these results, it is suggested that dietary PA beneficially modifies glucose and lipid metabolism in diabetic animals, and can potentially contribute to the mitigation of T2DM.

Key words: Pyroglutamic acid: Goto-Kakizaki rats: KK- $A^{y}$ mice: Type 2 diabetic mellitus

Pyroglutamic acid (PA) is an amino acid that is produced by the formation of a peptide bond between a $\gamma$-carboxyl group and an $\alpha$-amino group of glutamic acid (Fig. 1). PA is found in various foods such as vegetables, fruit and meat, and also in the human brain, spinal cord fluid and blood. For example, canned tomato juice, a processed food known to be rich in PA, contains $100-200 \mathrm{mg} \mathrm{PA} / 100 \mathrm{~g}^{(1)}$. It has been associated with the activity and generation of the neurotransmitter $\gamma$-aminobutyric acid or glycine, and its preventive effects against neuropathy ${ }^{(2)}$, tumour formation and metastasis ${ }^{(3)}$ have been reported. However, the effect of PA on type 2 diabetes mellitus (T2DM) has yet to be reported. In the present study, the anti-diabetic effect of dietary PA was examined in two T2DM rodents: non-obese GotoKakizaki (GK) rats and obese KK- $A^{y}$ mice. The effects of PA on the expression of genes involved in carbohydrate and lipid metabolism were also examined in the livers of GK rats.

GK rats are widely used in examining mechanisms for the development of $\mathrm{T}_{2} \mathrm{DM}^{(4-8)}$. These rats were bred by selective breeding of Wistar rats that had high blood glucose levels determined in an oral glucose tolerance test (OGTT) ${ }^{(9)}$. Between the ages of 3 and 4 weeks, the GK rats exhibit mild hyperglycaemia and hyperinsulinaemia. Insulin resistance $^{(10,11)}$, impaired insulin secretion ${ }^{(10)}$, abnormal glucose metabolism $^{(12)}$ and an impaired development of pancreatic islet cells ${ }^{(13)}$ are characteristics of diabetic GK rats. In contrast to other animal models of T2DM, GK rats are not obese and do not develop hyperlipidaemia ${ }^{(14)}$. By about the age of 24 months, these rats exhibit structural changes such as glomerular hypertrophy and thickening of the glomerular basement membrane, which also characterise the early stages of human diabetic nephropathy ${ }^{(15,16)}$.

$\mathrm{KK}-A^{y}$ mice are the result of cross-breeding between glucose-intolerant black KK female mice and yellow male obese $A^{y}$ mice, and are known to be an excellent model of obese $\mathrm{T}_{2} \mathrm{DM}^{(17)}$. These mice also provide a useful model system to study the pathogenesis and prevention of obesity and diabetes, and to investigate therapeutic approaches ${ }^{(18)}$.

Abbreviations: CON, control; CPT, carnitine palmitoyl transferase; FAS, fatty acid synthase; GK, Goto-Kakizaki; GLK, glucokinase; G6Pase, glucose-6phosphatase; G6PD, glucose-6-phosphate dehydrogenase; HDL-C, HDL-cholesterol; LDL-C, LDL-cholesterol; OGTT, oral glucose tolerance test; PA, pyroglutamic acid; T-chol, total cholesterol; T2DM, type 2 diabetes mellitus; 6PGD, 6-phosphogluconate dehydrogenase. 


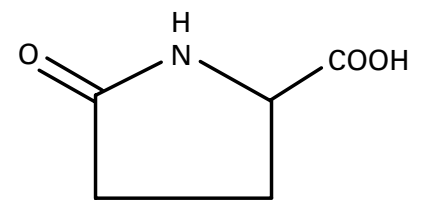

Fig. 1. Chemical structure of pyroglutamic acid.

In addition, these mice show polyphagia, polyposia, polyuria, hyperglycaemia, hyperinsulinaemia, insulin resistance and pancreas islet enlargement. The incidence of diabetes occurrence in 6-week-old male mice reaches $100 \%{ }^{(19)}$.

\section{Experimental methods}

\section{Animal care}

The present study was performed in accordance with the Animal Experimentation Guidelines of the Laboratory Animal Care Committee of Yamagata University. Rats and mice were individually housed in stainless-steel cages with screen bottoms. All animals were maintained on alternating $12 \mathrm{~h}$ light $-12 \mathrm{~h}$ dark cycles at a humidity of $40-60 \%$ and a temperature of $22 \pm 1^{\circ} \mathrm{C}$. Diet composition is shown in Table 1 . The daily intake of PA used in the present study was in accordance with Kimura et al. ${ }^{(3)}$; the amount corresponds to a daily intake of about $30 \mathrm{mg} \mathrm{PA} / \mathrm{kg}$ body weight. This quantity of PA can be obtained from food ${ }^{(1)}$. Diet and water were given ad libitum. PA was purchased from Kanto Chemical Co., Inc. (Tokyo, Japan).

\section{Experiments with Wistar rats}

The effect of dietary PA supplementation on non-diabetic animals was investigated by utilising Wistar rats. Male Wistar rats, aged 8 weeks, were purchased from Japan SLC, Inc. (Shizuoka, Japan). After an acclimatisation period of $3 \mathrm{~d}$, rats were placed on a basal diet (Wistar control group (WistarCON); $n$ 5) or a diet containing 0.05\% PA (Wistar-PA group; $n$ 6) for $46 \mathrm{~d}$. After feeding for 1 and 6 weeks, rats were fasted for $10 \mathrm{~h}$ and blood glucose levels were determined. At the end of the study, blood was collected from rats that had been fasted for $10 \mathrm{~h}$. The serum was prepared by centrifuging the collected blood at $1000 \mathrm{~g}$ for $15 \mathrm{~min}$ and analysed for lipid analysis and enzyme activities. The liver was removed and

Table 1. Composition of the experimental diets $(\%, w / w)$

\begin{tabular}{lll}
\hline Constituent & Basal diet & $\begin{array}{l}\text { Pyroglutamic } \\
\text { acid-containing diet }\end{array}$ \\
\hline Casein & 15 & 15 \\
$\alpha$-Maize starch-sucrose (2:1) & $70 \cdot 50$ & $70 \cdot 45$ \\
Maize oil & 5 & 5 \\
Cellulose & 5 & 5 \\
Mineral mixture* & 3.5 & 3.5 \\
Vitamin mixture $^{\star}$ & 1 & 1 \\
Pyroglutamic acid $_{\text {Total }}$ & - & 0.05 \\
\hline
\end{tabular}

${ }^{*}$ Mineral mix AIN-93G-MX and vitamin mix AIN-93-VX, which contained $25 \mathrm{~g}$ choline bitartrate per $100 \mathrm{~g}$, were obtained from Oriental Yeast Co. Ltd (Tokyo, Japan). stored at $-80^{\circ} \mathrm{C}$ until needed for analysis. The left kidney and left epididymal adipose tissues were also excised and weighed.

Serum alanine aminotransferase and aspartate aminotransferase activities were measured according to methods in the literature ${ }^{(20)}$.

Serum total cholesterol (T-chol), HDL-cholesterol (HDL-C) and TAG were measured enzymically with commercial kits (cholesterol E test, HDL-cholesterol test, triglyceride E test; Wako Pure Chemical Industries Ltd, Osaka, Japan). Serum LDL-cholesterol (LDL-C) level ${ }^{(21)}$ was calculated as:

$$
\text { LCD-C }=(\text { T-chol })-(\text { HDL-C })-(\text { TAG } / 5) .
$$

Atherogenic index ${ }^{(22)}$ was calculated as:

$$
\text { Atherogenic index }=((\text { T-chol })-(\text { HDL-C })) /(\text { HDL-C }) \text {. }
$$

Liver lipid was extracted by the method of Folch et $a l .{ }^{(23)}$, and measured by using the same kits as above.

\section{Experiments with Goto-Kakizaki rats}

The effect of dietary PA on non-obese T2DM rats was investigated by using the $\mathrm{GK}$ rat $(\mathrm{GK} / \mathrm{Slc})$. Male $\mathrm{GK}$ rats, aged 8 weeks, were purchased from CLEA Japan Inc. (Tokyo, Japan). After an acclimatisation period of $4 \mathrm{~d}$, rats were placed on a basal diet (GK-CON group; $n$ 6) or the diet containing $0.05 \%$ PA (GK-PA group; $n$ ) for $43 \mathrm{~d}$. As the nondiabetetic control group, five Wistar rats receiving the basal diet were used (Wistar group; $n$ )

The fasting blood glucose levels were measured as described above. After 26-27 d of dietary PA supplementation, an OGTT was performed. Before application of an oral glucose load ( $2 \mathrm{~g} / \mathrm{kg}$ body weight), blood glucose and serum insulin levels were determined in $10 \mathrm{~h}$ fasted rats. Blood glucose and serum insulin levels were measured 15, 30, 60 and $120 \mathrm{~min}$ after glucose application. The area under the curve was calculated for glucose during the OGTT. At the end of the study, blood was collected from the fasting rats. Serum was prepared as described above, and analysed for lipid, insulin and TNF- $\alpha$ levels. The liver was removed and stored at $-80^{\circ} \mathrm{C}$ until needed for assays, including enzyme activities and DNA microarray analysis. The left kidney and left epididymal adipose tissues were also excised and weighed. Serum insulin and TNF- $\alpha$ were determined by using ELISA kits (Levis rat insulin kit, Shibayagi Co., Ltd (Gunma, Japan); TNF $\alpha$ Biotrak ELISA kit, Amersham Biosciences Co. (Uppsala, Sweden)). Serum and liver lipid levels were measured as described above.

Liver enzyme activities including fatty acid synthase (FAS), glucose-6-phosphate dehydrogenase (G6PD), 6-phosphogluconate dehydrogenase (6PGD) and carnitine palmitoyl transferase (CPT) were measured as described below. To measure FAS activity, a liver homogenate was prepared by the Burton method ${ }^{(24)}$. FAS activity was determined in terms of malonyl-CoA- and acetyl-CoA-dependent oxidation of NADPH according to the methods of Kumer et $a l .{ }^{(25)}$ and Carey \& Dils ${ }^{(26)}$. The G6PD and 6PGD activities were measured with a Bioxytech G6PD/6PGD-340 kit (Oxis International Inc., 
Beverley Hills, CA, USA). To measure CPT activities, liver samples were homogenised in a $3 \mathrm{~mm}$-2-amino-2-hydroxymethyl-propane-1,3-diol (Tris)-HCl buffer ( $\mathrm{pH} 7 \cdot 2$ ) containing $0.25 \mathrm{~m}$-sucrose and $1 \mathrm{~mm}$-EDTA. The reaction mixture was composed of a $58 \mathrm{~mm}$-Tris-HCl buffer ( $\mathrm{pH} 8.0$ ) containing 0.25 mm-5,5'-dithio-bis (2-nitrobenzoic acid) (DTNB), 0.04 mmpalmitoyl CoA, $1.25 \mathrm{~mm}$-EDTA and $1.25 \mathrm{~mm}$-L-carnitine, and the homogenate. CPT activity was determined from the rate of change in absorbance at $412 \mathrm{~nm}^{(27)}$.

The influence of PA on gene expression related to carbohydrate and lipid metabolism was examined by DNA microarray analysis. RNA was isolated using an RNeasy Mini kit (Qiagen N. V., Hilden, Germany), and the total RNA was converted to cDNA using a WT Sense Target Labeling kit (NuGen Technologies Inc., San Carlos, CA, USA). The cDNA were hybridised onto GeneChip Array (Affymetrix, Inc., Santa Clara, CA, USA), Rat Gene 1.0 ST Array (27 342 genes) for $16 \mathrm{~h}$ at $45^{\circ} \mathrm{C}$, and scan and image data of arrays were acquired by a GeneChip 3000 Scanner (Affymetrix, Inc.). With a data analysis system utilising GeneChip Operating Software (Affymetrix, Inc.), the array image data of the acquired samples were confirmed. The selected genes were annotated based on NetAffx (linked at http://www.affymetrix.com). The classification of category was performed using the Kyoto Encyclopedia of Genes and Genomes (KEGG) database.

Furthermore, the gene expression of G6Pase, angiopoietinlike 4 and $\beta$-actin was also determined quantitatively by RTPCR. Primers were purchased from Sigma Aldrich Co. (St Louis, MO, USA). These were: glucose-6-phoshatase, sense, 5'-CTACCTTGCGGCTCACTTTC-3' , antisense, 5'-ATCCAAGTGCGAAACCAAAC- $3^{\prime}$; angiopoietin-like 4 , sense, $5^{\prime}$-CAGAACAG CAAGATCCAGCA- $3^{\prime}$, antisense, 5'-CCTCTTTCCCCTCGAAGTCT- $3^{\prime} ; \beta$-actin, sense, 5'-ACCCACACTGTGCCCATCTA- $3^{\prime}$, antisense, $5^{\prime}$-CGTCACACTTCATGATG- $3^{\prime}$.

Reactions were carried out in the LightCycler ${ }^{\circledR} 480$ System (Roche Applied Science Inc., Basel, Switzerland) using the SYBR Green Qiagen One-Step RT-PCR kit (Qiagen). The program profile was $95^{\circ} \mathrm{C}$ for $30 \mathrm{~s}$ and forty-five cycles of denaturation for $5 \mathrm{~s}$ at $95^{\circ} \mathrm{C}$, and annealing for $15 \mathrm{~s}$ at $55^{\circ} \mathrm{C}$ and extension for $15 \mathrm{~s}$ at $72^{\circ} \mathrm{C}$.

\section{Experiments with $K K-A^{y}$ mice}

The effect of dietary PA on obese T2DM animals was investigated in $\mathrm{KK}-A^{y}$ mice (KK- $\left.A^{y} / \mathrm{TaJcl}\right)$. Male $\mathrm{KK}-A^{y}$ mice, aged 6 weeks, were purchased from CLEA Japan Inc. After an acclimatisation period of $2 \mathrm{~d}$, mice were placed on a basal diet (KK- $A^{y}$-CON group; $n$ 8) or the diet containing $0.05 \%$ PA (KK- $A^{y}$-PA group (KKAy-PA); $n$ 7) for $28 \mathrm{~d}$. As non-diabetic control mice, seven $\mathrm{C} 57 \mathrm{BL} / 6 \mathrm{~J}$ mice receiving the basal diet were used (C57BL group).

Blood glucose levels in fasting (food-deprived for $12 \mathrm{~h}$ ) rats were measured on the first day of both week 1 and week 4 . After $22-23 \mathrm{~d}$ of treatment, the OGTT was carried out as described above. Blood glucose levels were measured at 30 , 60 and $120 \mathrm{~min}$, and insulin levels were measured at 30 and $60 \mathrm{~min}$ after glucose loading. At the end of the feeding period, all mice were bled, and the serum was prepared and stored at $-80^{\circ} \mathrm{C}$ until analysed for lipid, TNF- $\alpha$ and insulin levels. The liver was removed and stored at $-80^{\circ} \mathrm{C}$ until required for measuring enzyme activities. The left kidney and left epididymal adipose tissues were also excised and weighed. TNF- $\alpha$ levels were determined by an immunoassay kit (Invitrogen Co., Carlsbad, CA, USA). Serum and liver lipids were measured as described above.

FAS, G6PD + 6PGD and CPT activities of the livers were measured as described above. Glucokinase (GLK) activity was measured spectrophotometrically ${ }^{(28)}$. The liver sample was homogenised in an ice-cold buffer ( $\mathrm{pH} 7 \cdot 5)$ containing $50 \mathrm{~mm}$-HEPES, $250 \mathrm{~mm}$-sucrose, $100 \mathrm{~mm}-\mathrm{KCl}, \quad 1 \mathrm{~mm}$-EDTA, $5 \mathrm{mM}^{-\mathrm{MgCl}_{2}}$ and $2.5 \mathrm{~mm}$-dithioerythritol, and the homogenate was centrifuged at $105000 \boldsymbol{g}$ for $60 \mathrm{~min}$. Hexokinase activity of the supernatant fraction was measured in a buffer $(\mathrm{pH}$

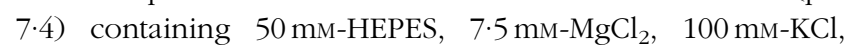
5 mM-ATP, 2.5 mm-dithioerythritol, bovine serum albumin $(10 \mathrm{mg} / \mathrm{ml}), 0.5 \mathrm{~mm}-\mathrm{NAD}^{+}$, glucose-6-phosphate dehydrogenase $(4 \mathrm{U} / \mathrm{ml})$ (L. mesenteroides) and $0.5 \mathrm{~mm}$-glucose. The total phosphorylating activity was measured by using $100 \mathrm{~mm}$-glucose instead of $0.5 \mathrm{~mm}$-glucose. The reaction was initiated by adding ATP, and the rate of increase in absorbance due to NADH formation was recorded at $340 \mathrm{~nm}$. GLK activity was calculated as the difference between the total phosphorylating activity and hexokinase activity. G6Pase activity was measured by using the microsomal fraction obtained as a precipitate by centrifugation at $105000 \mathrm{~g}$. The microsomal fraction was resuspended in a homogenisation buffer and diluted with an ice-cold buffer (pH 6.5) containing 100 mM-HEPES and $0 \cdot 1 \mathrm{~mm}$-EDTA. The reaction was initiated by adding $10 \mathrm{~mm}$ glucose-6-phosphate at $37^{\circ} \mathrm{C}$, and stopped after $20 \mathrm{~min}$ by adding $2 \cdot 2$ volumes of a solution containing $3.7 \mathrm{~mm}$-ammonium molybdate and $240 \mathrm{~mm}-\mathrm{SDS}$ in $270 \mathrm{~mm}-\mathrm{H}_{2} \mathrm{SO}_{4}$. After adding one-ninth of the volume of $1 \cdot 2 \mathrm{M}$-ascorbic acid, the reaction mixture was further incubated for $1 \mathrm{~h}$ at $37^{\circ} \mathrm{C}$, and the absorbance was measured at $820 \mathrm{~nm}^{(29)}$.

\section{Statistical analysis}

Data from animals in each group were expressed as mean values with their standard errors. The homogeneity of variance between treatments was verified by Bartlett's test. Data were statistically analysed by one-way ANOVA. A post hoc analysis of significance was made by using Fisher's protected least significant difference test, where differences were considered significant at $P<0 \cdot 05$.

Data of DNA microarray were statistically analysed by Welch's $t$ test and $P<0 \cdot 01$ was considered as statistically significant. False discovery rates were calculated according to Benjamini \& Hochberg ${ }^{(30)}$, and the threshold of false discovery rate was set at $5 \%$.

\section{Results}

\section{Evaluation in Wistar rats}

There were no differences among the two groups in bodyweight gains, weight of organs, fasting blood glucose, and 
serum and liver lipid levels (Table 2). As there were no differences in serum alanine aminotransferase and aspartate aminotransferase among the two groups, no inflammatory reactions in the liver were attributable to PA.

\section{Diabetes alleviation in Goto-Kakizaki rats}

The effects of PA in OGTT, which was determined after feeding the experimental diet for $26-27 \mathrm{~d}$, are shown in Fig. 2(A). The blood glucose levels at 15 and $30 \mathrm{~min}$ after glucose loading in the PA group did not differ from those of the GK-CON group. However, glucose levels at $60 \mathrm{~min}$ in the GK-PA group were significantly lower than in the GK-CON group. The areas under the curve of blood glucose levels are shown in Fig. 2(B). Values for the GK-PA group were significantly lower than for the GK-CON group. Dietary PA supplementation for $26-27 \mathrm{~d}$ improved the oral glucose tolerance in GK rats. The serum insulin levels during OGTT are shown in Fig. 2(C). The insulin level in the GK-CON group increased gradually from 0 to $120 \mathrm{~min}$. However, levels in the GK-PA group were significantly lower than those in the GK-CON group.

There was no significant difference in the total food intake among the groups; however, the body-weight gains of the GK-PA group tended to be lower than those of the GK-CON group $(P<0 \cdot 1)$ (Table 2). Although the liver and kidney weights did not differ, epididymal adipose tissue weights were lower in the GK-PA group than in the GK-CON group. The difference of these adipose weights might have been due to the decrease in body-weight gains of the GK-PA group. Fasting blood glucose levels did not differ between the GK-CON and GK-PA groups. The serum insulin level after the feeding period of $43 \mathrm{~d}$ was significantly lower in the GK-PA group than in the GK-CON group (Table 2).

The serum and liver lipid levels are shown in Table 2. The serum T-chol levels in the GK-PA group were significantly lower than in the GK-CON group, but HDL-C level did not differ between the two groups. The serum LDL-C and TAG levels in the GK-PA group were also significantly lower than in the GK-CON group. The liver T-chol and TAG levels in the GK-PA group were lower than in the GK-CON group, and resembled the results observed in the serum.

The ratio of signal intensity of the 27342 genes in the GK-PA group to those in the GK-CON group was calculated. Genes with a 2 -fold ratio increase were defined arbitrarily as upregulated genes in the GK-PA group, whereas those with a ratio decreased by one-half or more were defined as downregulated genes. When compared with the GK-CON group, nine genes were up-regulated and twenty-nine were downregulated in the GK-PA group (see Supplemental table; available at http://www.journals.cambridge.org/bjn). Furthermore, we listed the genes in the two functional categories of carbohydrate metabolism and lipid metabolism (Table 3).

Table 2. Effects of pyroglutamic acid (PA) in Wistar and Goto-Kakizaki (GK) rats

(Mean values with their standard errors)

\begin{tabular}{|c|c|c|c|c|c|c|c|c|}
\hline \multirow{3}{*}{ Dietary group... } & \multicolumn{4}{|c|}{ Wistar rats $†$} & \multicolumn{4}{|c|}{ GK ratsł } \\
\hline & \multicolumn{2}{|c|}{ Wistar-CON $(n 5)$} & \multicolumn{2}{|c|}{ Wistar-PA $(n 6)$} & \multicolumn{2}{|c|}{ GK-CON $(n 6)$} & \multicolumn{2}{|c|}{ GK-PA $(n 5)$} \\
\hline & Mean & SEM & Mean & SEM & Mean & SEM & Mean & SEM \\
\hline Initial body weight (g) & 179 & 3 & 180 & 2 & 205 & 11 & 214 & 16 \\
\hline Body-weight gain (g) & 104.4 & 4.5 & $108 \cdot 6$ & 3.8 & $108 \cdot 3$ & $6 \cdot 0$ & 98.9 & $5 \cdot 1$ \\
\hline \multicolumn{9}{|l|}{ Organs (\% body weight) } \\
\hline Liver & $3 \cdot 14$ & 0.08 & $3 \cdot 12$ & 0.08 & 3.44 & 0.09 & 3.28 & 0.13 \\
\hline Kidney & 0.33 & 0.01 & 0.32 & 0.01 & 0.42 & 0.01 & 0.41 & 0.01 \\
\hline \multicolumn{8}{|l|}{ Fasting blood glucose $(\mathrm{mg} / \mathrm{l})$} & 0.09 \\
\hline Week 1 & 684 & 80 & 707 & 55 & 1177 & 30 & 1184 & 82 \\
\hline Week 6 & 938 & 27 & 925 & 57 & 1123 & 27 & 1160 & 40 \\
\hline Serum insulin (pg/ml) & ND & & ND & & 116.9 & 4.9 & $99.0^{*}$ & 2.9 \\
\hline Serum TNF- $\alpha(\mathrm{pg} / \mathrm{ml})$ & ND & & ND & & $123 \cdot 2$ & 3.7 & $115 \cdot 1$ & 1.0 \\
\hline \multicolumn{9}{|c|}{ Serum enzymes ( $\mu \mathrm{mol} / \mathrm{min}$ per litre) } \\
\hline ALT & 44.5 & $10 \cdot 2$ & $42 \cdot 0$ & $7 \cdot 9$ & ND & & ND & \\
\hline AST & 74.9 & $6 \cdot 7$ & 79.5 & 5.9 & ND & & ND & \\
\hline \multicolumn{9}{|l|}{ Serum lipids (mg/l) } \\
\hline Total cholesterol & 1065 & 60 & 1139 & 52 & 1233 & 215 & $938^{*}$ & 36 \\
\hline HDL-cholesterol & 405 & 40 & 384 & 19 & 727 & 34 & 662 & 34 \\
\hline LDL-cholesterol & 464 & 39 & 544 & 32 & 669 & 167 & $204^{*}$ & 62 \\
\hline TAG & 977 & 149 & 1049 & 174 & 909 & 166 & $358^{*}$ & 39 \\
\hline Atherogenic index & 0.62 & 0.02 & 0.66 & 0.02 & 0.68 & 0.27 & 0.43 & 0.14 \\
\hline Total cholesterol & $1 \cdot 31$ & 0.09 & 1.39 & 0.04 & 4.96 & 0.64 & $3.91^{\star}$ & 0.59 \\
\hline TAG & 8.95 & $1 \cdot 15$ & $9 \cdot 77$ & 0.71 & $52 \cdot 2$ & 8.5 & $18 \cdot 8^{\star}$ & $5 \cdot 8$ \\
\hline
\end{tabular}

CON, control; ND, not determined; ALT, alanine aminotransferase; AST, aspartate aminotransferase.

${ }^{*}$ Mean value was significantly different from that of the GK-CON group $(P<0.05)$.

† Wistar rats were fed a control diet or supplemented with $0.05 \%$ PA for $46 \mathrm{~d}$.

‡GK rats were fed a control diet or supplemented with $0.05 \%$ PA for $43 \mathrm{~d}$. 

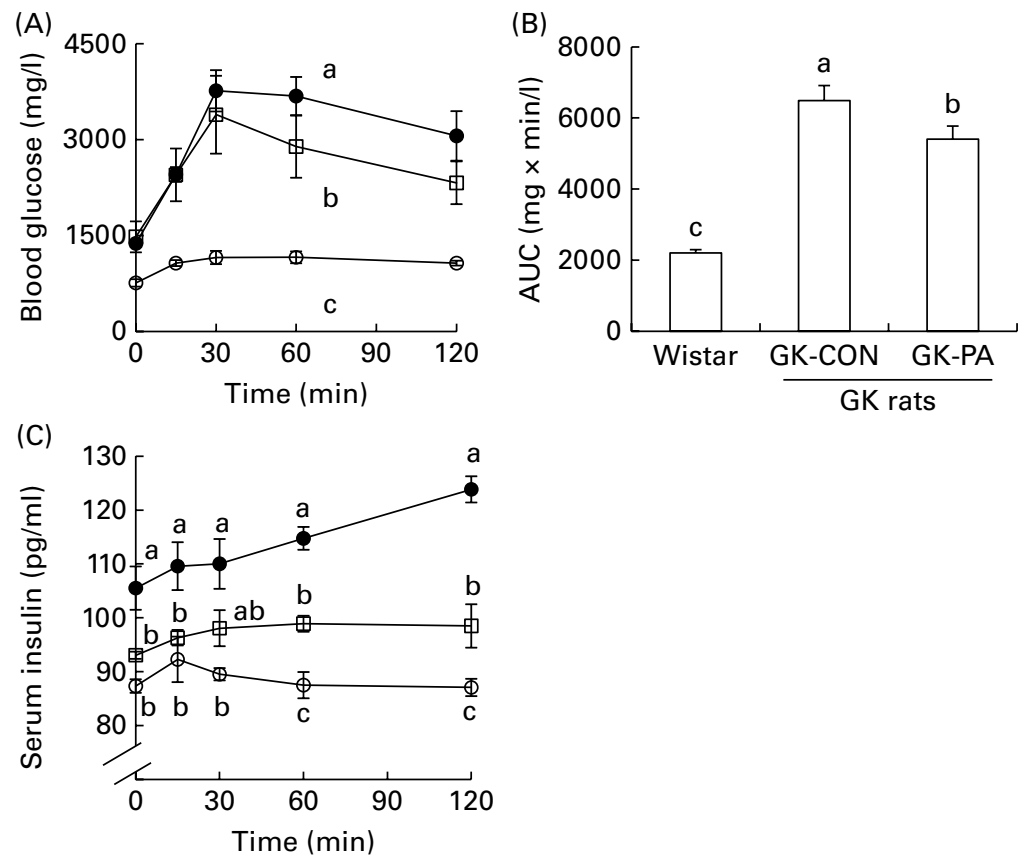

Fig. 2. (A) Blood glucose during an oral glucose tolerance test (OGTT) in Wistar rats $(-\bigcirc-; n 5)$, Goto-Kakizaki (GK) rats fed a control (CON) diet (GK-CON $-\bullet-; n 6$ ) and GK rats fed a diet supplemented with $0.05 \%$ pyroglutamic acid (PA) (GK-PA; $-\square-; n$ ) for $26-27$ d. (B) Calculated areas under the curve (AUC) of blood glucose in Wistar and GK rats. (C) Insulin levels during an OGTT in Wistar, GK-CON and GK-PA rats. Values are means, with standard errors represented by vertical bars. ${ }^{\mathrm{a}, \mathrm{b}, \mathrm{c}}$ Mean values with unlike letters were significantly different $(P<0.05)$.

Genes involved in glycolysis (GLK) and gluconeogenesis (G6Pase) and the gene for the transcription factor forkhead box $\mathrm{O} 1$ were down-regulated; the gene expression of pyruvate dehydrogenase kinase 4 was up-regulated. With respect to the expression of genes concerned with lipid metabolism, downregulation was found in the following: angiopoietin-like 4, and the fatty acid metabolism enzymes cytochrome P450, family 4, subfamily a. Gene expressions of PPAR $\alpha$ (gene symbol: Ppara) and sterol regulatory element-binding protein (gene symbol: Srebf1), which are carbohydrate and lipid metabolism-related, in the GK-PA group did not change when compared with those of the GK-CON group (fold change: Ppara, 0.71; Srebf1, 0.82). Furthermore, gene expressions of insulin receptor substrate 2 (gene symbol:
Irs-2) and phosphatidylinositol 3-kinase (gene symbol: Pik3r1), insulin signalling pathway-related genes, also did not differ between the GK-PA and GK-CON groups (fold change: Irs-2, 0.88; Pik3r1, 0.84). Down-regulation of G6Pase and angiopoietin-like 4 in the GK-PA group was also observed when determined by RT-PCR (G6Pase (GK-CON $v$. GK-PA), 1.00 (SEM 0.08) v. 0.44 (SEM 0.02); angiopoietin-like 4, 1.00 $(\operatorname{SEM} 0 \cdot 12) v \cdot 0 \cdot 52(\operatorname{SEM} 0 \cdot 07))$.

The activities of the liver enzymes FAS, G6PD +6PGD and CPT are shown in Table 4. The GK-PA group showed significantly lower levels of FAS activity than the GK-CON group. On the other hand, CPT activity was significantly higher in the GK-PA group when compared with the Wistar and GK-CON groups. From the DNA microarray analysis, the expression

Table 3. DNA microarray analysis of Goto-Kakizaki (GK) rat liver after treatment with $0.05 \%$ pyroglutamic acid for $43 \mathrm{~d}^{*}$ (Mean values for three independent experiments)

\begin{tabular}{|c|c|c|}
\hline Glycolysis and gluconeogenesis & Glucokinase & 0.39 \\
\hline Fructose and mannose metabolism & 6-Phosphofructo-2-kinase/fructose-2,6-biphosphatase 1 & 0.50 \\
\hline \multirow[t]{2}{*}{ Glycan biosynthesis and metabolism } & ST3 $\beta$-galactoside $\alpha$ 2,3-sialyltransferase 1 & 0.50 \\
\hline & Phosphatidylinositol glycan anchor biosynthesis, class W & 0.50 \\
\hline Insulin signalling pathway & Forkhead box $\mathrm{O} 1$ & 0.42 \\
\hline PPAR signalling pathway & Angiopoietin-like 4 & 0.50 \\
\hline \multirow[t]{2}{*}{ Fatty acid metabolism } & Cytochrome P450, family 4, subfamily a, polypeptide 2 & $2 \cdot 01$ \\
\hline & Cytochrome P450, family 4 , subfamily a, polypeptide 3 & $2 \cdot 02$ \\
\hline Primary bile acid biosynthesis & Cytochrome P450, family 7 , subfamily a, polypeptide 1 & 0.24 \\
\hline
\end{tabular}

* Selected genes involved in lipid, glucose metabolism were compared with those from GK rats given the control diet. $\dagger$ Value relative to control group. 
Table 4. Liver fatty acid synthase (FAS), glucose-6-phosphate dehydrogenase (G6PD) +6-phosphogluconate dehydrogenase (6PGD) and carnitine palmitoyl transferase (CPT) activities in Goto-Kakizaki (GK) rats and $\mathrm{KK}-A^{y}$ mice

(Mean values with their standard errors)

\begin{tabular}{|c|c|c|c|c|c|c|}
\hline & \multicolumn{2}{|c|}{$\begin{array}{c}\text { FAS } \\
\text { (mol/h per kg liver) }\end{array}$} & \multicolumn{2}{|c|}{$\begin{array}{c}\text { G6PD +6PGD } \\
(\mathrm{mU} / \mathrm{ml})\end{array}$} & \multicolumn{2}{|c|}{$\begin{array}{c}\text { CPT } \\
\text { (mU/g liver) }\end{array}$} \\
\hline & Mean & SEM & Mean & SEM & Mean & SEM \\
\hline \multicolumn{7}{|l|}{ GK rats* } \\
\hline Wistar & $3 \cdot 31^{a}$ & 0.27 & 8.27 & 1.54 & $0.59^{b}$ & 0.14 \\
\hline GK-CON & $3 \cdot 29^{a}$ & 0.43 & 8.89 & 1.51 & $0.34^{\mathrm{b}}$ & 0.09 \\
\hline GK-PA & $1.08^{b}$ & 0.26 & $5 \cdot 10$ & 0.88 & $1.42^{\mathrm{a}}$ & 0.10 \\
\hline \multicolumn{7}{|l|}{$\mathrm{KK}-A^{y}$ mice $\dagger$} \\
\hline C57BL & $1.04^{\mathrm{a}}$ & 0.16 & $116 \cdot 9^{\mathrm{a}}$ & 3.9 & 0.27 & 0.05 \\
\hline KKAy-CON & $0.98^{\mathrm{a}}$ & 0.26 & $79 \cdot 0^{\mathrm{b}}$ & $3 \cdot 7$ & 0.20 & 0.05 \\
\hline KKAy-PA & $0.35^{b}$ & 0.11 & $74 \cdot 8^{\mathrm{b}}$ & $3 \cdot 6$ & 0.21 & 0.05 \\
\hline
\end{tabular}

CON, control; PA, pyroglutamic acid.

a,b Within a study, mean values within a column with unlike superscript letters were significantly different $(P<0.05)$.

* Wistar and GK-CON groups were administered the basal diet. The GK-PA group was administered a $0.05 \%$ PA-containing diet for $43 \mathrm{~d}$.

† C57BL and KKAy-CON groups were administered the basal diet. The KKAy-PA group was administered a $0.05 \%$ PA-containing diet for $28 \mathrm{~d}$.

of the CPT gene in the GK-PA group increased in comparison with the GK-CON group (fold change 1.72), and the FAS gene in the GK-PA group decreased (0.62).

\section{Diabetes alleviation in $K K-A^{y}$ mice}

In OGTT, the blood glucose levels in the KKAy-CON group were higher from 0 to $120 \mathrm{~min}$ after glucose loading, but the
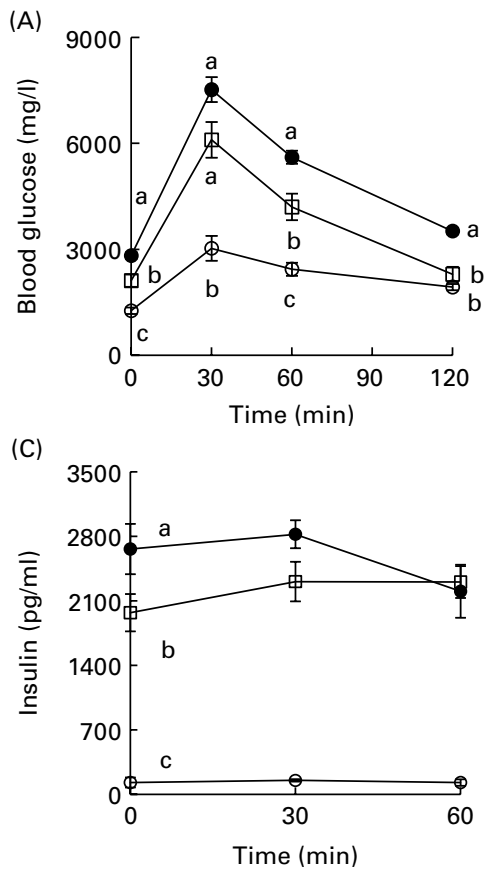

rises were suppressed at 60 and $120 \mathrm{~min}$ in the KKAy-PA group (Fig. 3(A)). The blood glucose level before the glucose load of OGTT in the KKAy-PA group was significantly lower than in the KKAy-CON group. It is considered that the significant, difference relates to the fasting blood glucose level at week 4. Serum insulin level in the KKAy-PA group, which was measured just before glucose loading, was significantly lower than that in the KKAy-CON group (Fig. 3(C)). However, the insulin level at 30 and $60 \mathrm{~min}$ after glucose loading did not differ between the two groups. Homeostatic model assessment of insulin resistance level (HOMA-IR), an insulin resistance index, was significantly lower in the KKAy-PA group than in the KKAy-CON group (Fig. 3(D)). These results suggest that the KKAy-CON group became insulin resistant, and that insulin resistance was reduced in the KKAy-PA group.

The body-weight gains in the KKAy-PA group were significantly higher than those in the KKAy-CON group in spite of the total food intake not differing between the $\mathrm{KK}-A^{y}$ (KKAy-CON and KKAy-PA) groups (Table 5). Although the liver and kidney weights did not differ, epididymal adipose tissue weights were lower in the KKAy-CON group than in the KKAy-PA group. The fasting blood glucose level after 4 weeks was significantly lower in the KKAy-PA than in the KKAy-CON group (Table 5). The rises observed in serum insulin and TNF- $\alpha$ levels in the KKAy-CON group were suppressed in the KKAy-PA group (Table 5).

Serum and liver lipid levels are shown in Table 5. The serum T-chol and LDL-C levels in the KKAy-PA group were significantly lower than in the KKAy-CON group. The liver

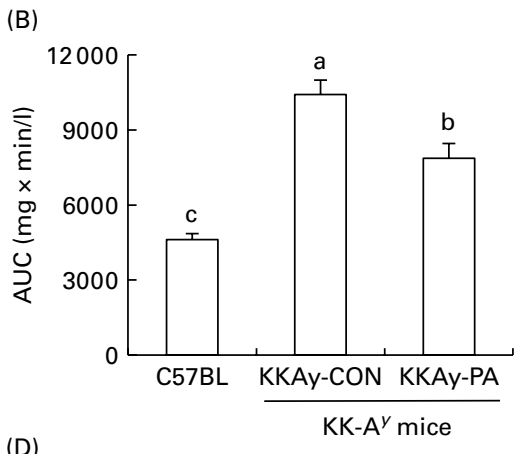

(D)

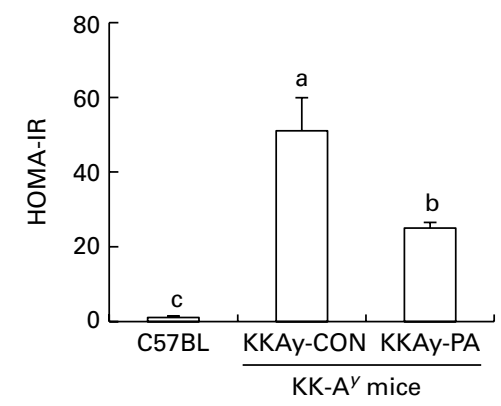

Fig. 3. (A) Blood glucose during an oral glucose tolerance test (OGTT) in 9-week-old C57BL mice (-O-; $n 7)$, KK- $A^{y}$ mice fed a control (CON) diet (KKAy-CON; - $-; n$ ) and KK- $A^{y}$ mice fed a diet supplemented with $0.05 \%$ pyroglutamic acid (PA) (KKAy-PA; $-\square-; n 7$ ) for 22-23d. (B) Calculated areas under the curve (AUC) of blood glucose in C57BL and KK- $A^{y}$ mice. (C) Insulin levels during an OGTT in C57BL, KKAy-CON and KKAy-PA mice. (D) homeostatic model assessment of insulin resistance (HOMA-IR) values in C57BL and KK- $A^{y}$ mice. HOMA-IR was calculated by the following formula: ((fasting blood glucose (mg/dl) $\times$ fasting serum insulin $(\mu \mathrm{U} / \mathrm{ml})) / 405)$. Values are means, with standard errors represented by vertical bars. ${ }^{\text {a,b,c }}$ Mean values with unlike letters were significantly different $(P<0.05)$. 
Table 5. Effects of pyrogutamic acid (PA) in KK- $A^{\mathrm{y}}$ mice

(Mean values with their standard errors)

\begin{tabular}{|c|c|c|c|c|c|c|}
\hline & & & \multicolumn{4}{|c|}{$\mathrm{KK}-A^{y}$ mice ${ }^{*}$} \\
\hline & \multicolumn{2}{|c|}{ 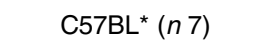 } & \multicolumn{2}{|c|}{ KKAy-CON $(n 8)$} & \multicolumn{2}{|c|}{ KKAy-PA $(n 7)$} \\
\hline & Mean & SEM & Mean & SEM & Mean & SEM \\
\hline Initial body weight $(\mathrm{g})$ & $19 \cdot 4$ & 0.3 & $27 \cdot 1$ & 0.5 & $27 \cdot 0$ & 0.3 \\
\hline Body-weight gain (g) & $7 \cdot 1^{\mathrm{c}}$ & 0.4 & $10 \cdot 1^{b}$ & 0.5 & $12 \cdot 2^{\mathrm{a}}$ & 0.6 \\
\hline Cumulative food intake (g) & 132 & 3 & 160 & 4 & 164 & 4 \\
\hline \multicolumn{7}{|l|}{ Organs (\% body weight) } \\
\hline Liver & $4 \cdot 23^{\mathrm{b}}$ & 0.07 & $4.58^{\mathrm{a}}$ & 1.47 & $4 \cdot 35^{a, b}$ & 0.09 \\
\hline Kidney & $0.61^{b}$ & 0.02 & $0 \cdot 70^{\mathrm{a}}$ & 0.02 & $0.72^{\mathrm{a}}$ & 0.01 \\
\hline Epididymal adipose tissue & $1.04^{c}$ & 0.07 & $1.85^{b}$ & 0.10 & $2 \cdot 13^{\mathrm{a}}$ & 0.10 \\
\hline \multicolumn{7}{|l|}{ Fasting blood glucose $(\mathrm{mg} / \mathrm{l})$} \\
\hline Week 1 & 707 & 89 & 873 & 138 & 866 & 143 \\
\hline Week 4 & $1260^{c}$ & 92 & $2820^{a}$ & 372 & $2111^{\mathrm{b}}$ & 173 \\
\hline Serum insulin (pg/ml) & $483^{\mathrm{c}}$ & 103 & $2328^{a}$ & 304 & $1308^{\mathrm{b}}$ & 267 \\
\hline Serum TNF- $\alpha(\mathrm{pg} / \mathrm{ml})$ & $6 \cdot 89^{c}$ & $2 \cdot 16$ & $34 \cdot 10^{\mathrm{a}}$ & 3.61 & $15 \cdot 79^{\mathrm{b}}$ & 1.96 \\
\hline \multicolumn{7}{|l|}{ Serum lipids (mg/l) } \\
\hline Total cholesterol & $1081^{\mathrm{b}}$ & 170 & $1641^{\mathrm{a}}$ & 182 & $1075^{\mathrm{b}}$ & 99 \\
\hline HDL-cholesterol & $268^{\mathrm{b}}$ & 21 & $278^{\mathrm{b}}$ & 35 & $497^{\mathrm{a}}$ & 48 \\
\hline LDL-cholesterol & $735^{\mathrm{b}}$ & 175 & $1236^{a}$ & 184 & $463^{b}$ & 134 \\
\hline TAG & $388^{\mathrm{b}}$ & 61 & $633^{a}$ & 55 & $573^{a}$ & 74 \\
\hline Atherogenic index & $3 \cdot 18^{a, b}$ & 0.81 & $5 \cdot 86^{a}$ & 1.31 & $1 \cdot 36^{b}$ & 0.38 \\
\hline \multicolumn{7}{|l|}{ Liver lipids (mg/g liver) } \\
\hline Total cholesterol & $0.48^{\mathrm{c}}$ & 0.16 & $2 \cdot 80^{\mathrm{a}}$ & 0.31 & $2 \cdot 18^{\mathrm{b}}$ & 0.16 \\
\hline TAG & $13 \cdot 9^{b}$ & 1.2 & $26 \cdot 2^{\mathrm{a}}$ & $2 \cdot 5$ & $21 \cdot 5^{\mathrm{a}}$ & 1.9 \\
\hline
\end{tabular}

T-chol level in the K-PA group was significantly lower than in the KKAy-CON group. However, unlike the studies in the GK rats, serum and liver TAG levels in the KKAy-PA group were similar to those in the KKAy-CON group.

The activities of the liver FAS, G6PD + 6PGD and CPT enzymes are shown in Table 4. FAS activity in the KKAy-PA group was significantly lower than in the KKAy-CON group. On the other hand, G6PD +6PGD and CPT activities were not different between the KKAy-CON and KKAy-PA groups. The liver GLK and G6Pase activities in the KKAy-PA group were significantly lower than those in the KKAy-CON group (Fig. 4). When the GLK:G6Pase ratios, which show the the magnitude of glycolysis and gluconeogenesis, were compared the ratio in the KKAy-PA group was significantly higher than that in the KKAy-CON group.

\section{Discussion}

In the Wistar rats without diabetes, dietary PA did not affect the diabetic markers and lipid levels, including the liver damage marker. These results may suggest that the intake of PA does not have an influence on non-diabetic rats.

Although food intake did not differ among GK rats, bodyweight gains in the GK-CON group tended to be higher than in the GK-PA group on day 43. After feeding of the experimental diets for $21 \mathrm{~d}$, the body-weight gains in the GK-PA group were significantly lower than in the GK-CON group, and the body-weight gains in the GK-PA group showed a similar value to that of the Wistar group (data not shown). As the epididymal adipose tissue weight in the GK-PA group was less than that in the GK-CON group, lower body-weight gains may be associated with a decrease in this tissue weight.

The experiments with the GK rats suggested that the feeding of PA resulted in an improvement in glucose tolerance. Reduction of insulin resistance in T2DM by PA may be associated with suppression of G6Pase gene expression, because the gene expression of G6Pase in the GK-PA group was downregulated as compared with the GK-CON group when measured by DNA microarray analysis. This is considered to be closely related to a lower gene expression of transcriptional glycogenic activators (forkhead box O1). The mRNA levels of GLK in the GK-PA group were lower than in the GK-CON group, supporting the result of a lower blood glucose level in the GK-PA group than in the GK-CON group. In addition, it is considered that a lower expression of angiopoietin-like 4 (Angptl4) in the GK-PA group lowers the TAG level significantly. $\mathrm{Li}^{(31)}$ and Köster et al. ${ }^{(32)}$ have reported that Angptl4 has been shown to inhibit lipoprotein lipase (LPL) activity and increase plasma TAG. In the GK-PA group, it may be considered that the constitution of the lipoprotein (for example, HDL-C, chylomicron or VLDL-cholesterol levels) was being changed through the activation of LPL.

In the experiment with the KK- $A^{\mathrm{y}}$ mice, G6Pase activity in the KKAy-PA group was lower than in the KKAy-CON group, resulting in a higher GLK:G6Pase (activity) ratio in the KKAy-PA group. The higher GLK:G6Pase ratio in the GK-PA group may indicate the regulation of glycolysis by PA. It has been reported that T2DM causes an increase in glucose levels that is associated with hyperglycaemia, and that inhibition of hepatic gluconeogenesis suppresses an increase 

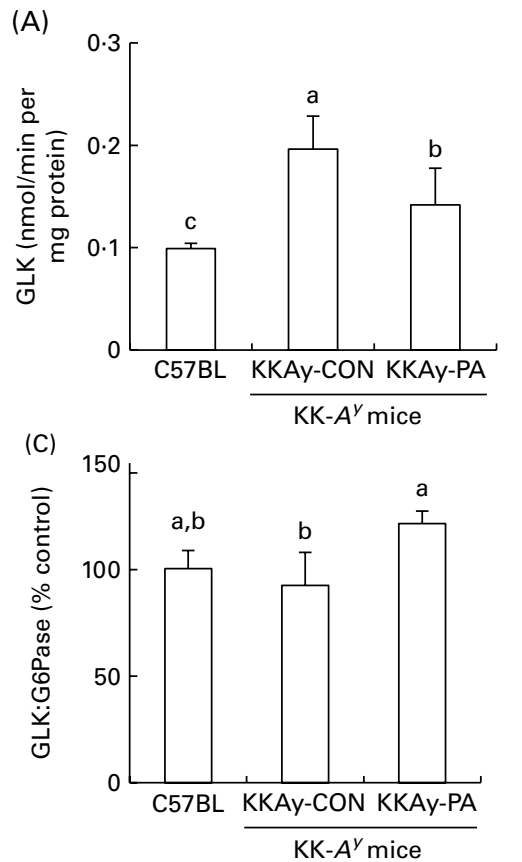

(B)

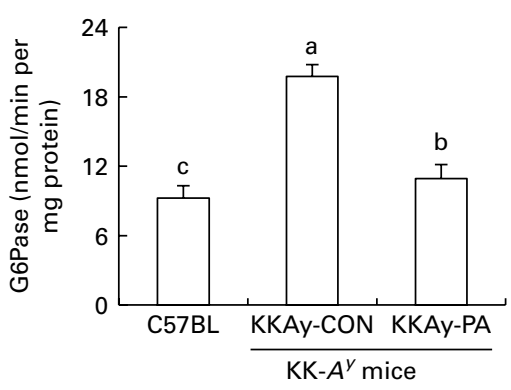

Fig. 4. Effects of pyroglutamic acid (PA) on liver glucokinase (GLK) (A) and glucose-6-phosphatase (G6Pase) (B) activities, and relative activity of GLK to G6Pase (GLK:G6Pase) (C) in C57BL mice ( $n$ 7), KK- $A^{y}$ mice fed a control diet (KKAy-CON; $n$ 8) and KK- $A^{y}$ mice fed a diet containing $0.05 \%$ PA (KKAy-PA; $n 7$ ) for $28 \mathrm{~d}$. Values are means, with standard errors represented by vertical bars. ${ }^{\mathrm{a}, \mathrm{b}, \mathrm{c}}$ Mean values with unlike letters were significantly different $(P<0.05)$.

in fasting plasma glucose levels and also decreases endogenous glucose production in T2DM patients ${ }^{(33-35)}$. The higher GLK:G6Pase ratio in the KKAy-PA group further supports the idea that PA may be available to suppress the increase in plasma glucose levels. The mechanism of the anti-diabetes effects in both GK rats and KK- $A^{y}$ mice is related to gluconeogenesis and glycolysis.

The body-weight gains of the KK- $A^{\mathrm{y}}$ mice were different from those of the GK rats. Although the total food intakes did not differ among KK- $A^{y}$ mice, the body-weight gains in the KKAy-CON group were significantly lower than in the KKAy-PA group. As the epididymal adipose tissue weights in the KKAy-CON group were less than in the KKAy-PA group, therefore, lower body-weight gains may be associated with a decrease in this tissue weights. In addition, although the serum and liver TAG levels in the GK-PA group were lower than in the GK-CON group, those in the KK- $A^{y}$ mice did not differ significantly between the KKAy-CON and KKAy-PA groups. When the activities of enzymes concerned with lipid metabolism were measured, the FAS activities of the animals fed PA were significantly lower than the CON animals in both GK rats and KK- $A^{y}$ mice. In the GK rats, the CPT activities in the GK-PA group were higher than those in the GK-CON group, but there was no difference between the two groups in the KK- $A^{y}$ mice. These results suggest that PA is effective in inhibiting the accumulation of lipids in animals without severe obesity, such as in GK rats. Higher CPT activities in the GK-PA group compared with the GK-CON group suggest that lower body weight in the GK-PA group was the result of inhibiting the accumulation of fatty acids by PA. However, the reason for the higher body-weight gains in the
KKAy-PA group than in the KKAy-CON group in the KK- $A^{y}$ mice study needs to be examined in the future. Hofmann et al. reported that the body weight of KK- $A^{y}$ mice decreased when diabetes accompanied with insulin resistance progressed, and that animals treated with an insulin-sensitising agent (pioglitazone) gained body weight ${ }^{(36)}$. In severe insulin resistance, a condition is induced wherein the intake of glucose is prevented in the liver, muscle and adipose tissue. It is conceivable that protein and lipid are used as energy sources instead of glucose. This metabolic change in the KKAy-PA group might account for the higher weight gain than in the KKAy-CON group.

Effects of PA on TNF- $\alpha$ levels also showed differences between $\mathrm{GK}$ rats and $\mathrm{KK}-A^{\mathrm{y}}$ mice. In the experiment with GK rats, TNF- $\alpha$ levels in the GK-PA group were no different from those in the GK-CON group. However, in KK- $A^{\mathrm{y}}$ mice, TNF- $\alpha$ levels of mice fed PA were significantly lower than in the KKAy-CON group, suggesting that TNF- $\alpha$ is produced from macrophages migrated to an enlarged fat cell ${ }^{(37)}$. However, there is no equilateral correlation between TNF- $\alpha$ levels and adipose weights in the present experiment. In the KKAy-PA group, the epididymal adipose weights were higher, but the size of the cells may be smaller than in the KKAy-CON group. Equilateral correlation in TNF- $\alpha$ levels and homeostatic model assessment of insulin resistance in the $\mathrm{KK}-A^{\mathrm{y}}$ mouse experiment was found. Because TNF- $\alpha$ is one of the factors that causes insulin resistance ${ }^{(38,39)}$, dietary PA intake inhibited one factor associated with insulin resistance.

From these results, we conclude that dietary PA is available to mitigate diabetes by diminishing insulin resistance, and serum and liver lipid levels, and by regulating the gene 
expression of glucose and lipid metabolism. Though nonobesity or obesity type, some mechanisms seem to be different for an anti-diabetic or an anti-hyperlipidaemic effect. In addition, side effects in long-term use and antidiabetic effects in human consumers are not known. A further study will be necessary in the future.

\section{Acknowledgements}

No funding was received.

O. Y. designed and conducted the research, analysed data and wrote the paper. K. I. had primary responsibility for the final content. All authors read and approved the final manuscript.

There are no conflicts of interest to disclose.

\section{References}

1. Marconi O, Floridi S \& Montanari L (2007) Organic acids profile in tomato juice by HPLC with UV detection. J Food Qual 30, $43-56$.

2. Silva AR, Silva CG, Ruschel C, et al. (2001) L-Pyroglutamic acid inhibits energy production and lipid synthesis in cerebral cortex of young rats in vitro. Neurochem Res 26, $1277-1283$.

3. Kimura Y, Kido T, Takaku T, et al. (2004) Isolation of an antiangiogenic substance from Agaricus blazei Murill: its antitumor and antimetastatic actions. Cancer Sci 95, 758-764.

4. Goto Y, Kakizaki M \& Masaki N (1976) Production of spontaneous diabetic rats by repetition of selective breeding. Tohoku J Exp Med 119, 85-90.

5. Sandu OA, Ragolia L \& Begum N (2000) Diabetes in the Goto-Kakizaki rat is accompanied by impaired phosphatase activation and vascular smooth muscle cell relaxation. Diabetes 49, 2178-2189.

6. Jacob A, Smolenski A, Lohmann SM, et al. (2004) MKP-1 expression and stabilization and $\mathrm{CGK}$ I $\alpha$ prevent diabetesassociated abnormalities in VSMC migration. Am J Physiol Cell Physiol 287, C1077-C1086.

7. Rose T, Efendic S \& Rupnik M (2007) $\mathrm{Ca}^{2+}$-secretion coupling is impaired in diabetic Goto Kakizaki rats. J Gen Physiol 129, 493-508.

8. Bitar MS, Al-Saleh E \& Al-Mulla F (2005) Oxidative stressmediated alterations in glucose dynamics in a genetic animal model of type II diabetes. Life Sci 77, 2552-2573.

9. Goto Y, Kakizaki M \& Masaki N (1975) Spontaneous diabetes produced by selective breeding of normal Wistar rats. Proc Jpn Acad 51, 80-85.

10. Bisbis S, Bailbe D, Tormo MA, et al. (1993) Insulin resistance in the GK rat: decreased receptor number but normal kinase activity in liver. Am J Physiol 265, E807-E813.

11. Picarel-Blanchot F, Berthelier C, Bailbe D, et al. (1996) Impaired insulin secretion and excessive hepatic glucose production early events in the diabetic GK rat. Am J Physiol 271, E755-E762.

12. Ostenson CG, Khan A, Abdel-Halim SM, et al. (1993) Abnormal insulin pancreatic islets from the spontaneously diabetic GK rat. Diabetologia 36, 3-8.

13. Movassat J, Saulnier C, Serradas P, et al. (1997) Impaired development of pancreatic $\beta$-cell mass is a primary event during the progression to diabetes in the GK rat. Diabetologia 40, 916-925.
14. Janssen U, Vassiliadou A, Riley SG, et al. (2004) The quest for a model of type II diabetes with nephropathy: the Goto Kakizaki rat. J Nephrol 17, 769-773.

15. Phillips AO, Baboolal K, Riley S, et al. (2001) Association of prolonged hyperglycemia with glomerular hypertrophy and renal basement membrane thickening in the Goto Kakizaki model of non-insulin-dependent diabetes mellitus. Am J Kidney Dis 37, 400-410.

16. Mauer SM, Steffes MW, Ellis EN, et al. (1984) Structuralfunctional relationships in diabetic nephropathy. J Clin Invest 74, 1143-1155.

17. Chang AY, Wyse BM, Copeland EJ, et al. (1986) The Upjohn colony of KKAy mice: a model for obese type II diabetes. In Diabetes, pp. 466-470 [M Serrano-Rios and PJ Lefebure, editors]. Amsterdam: Elsevier.

18. Herberg L \& Coleman DL (1977) Laboratory animals exhibiting obesity and diabetes syndromes. Metabolism 26, 59-99.

19. Iwatsuka H, Shino A \& Suzuoki Z (1970) General survey of diabetic features of yellow KK mice. Endocrinol Jpn 17, 23-35.

20. Matsumoto K (1981) Transaminase. In Protein, Nucleic Acid and Enzyme (in Japanese), pp. 94-97 [K Ogata, T Inoue, K Matsumoto and S Uemura, editors]. Tokyo: Kyoritu Shuppan.

21. Friedewald WT, Levy RI \& Fredrickson DS (1972) Estimation of the concentration of low-density lipoprotein cholesterol in plasma, without use of the preparative ultracentrifuge. Clin Chem 18, 499-502.

22. Choi JS, Yokozawa T \& Oura H (1991) Antihyperlipidemic effect of flavonoids from Prunus davidiana. J Nat Prod 54, 218-224.

23. Folch JL, Lees M \& Sloane Stanley GH (1957) A simple method for the isolation and purification of total lipides from animal tissues. J Biol Chem 226, 497-506.

24. Burton DN, Haavis AG \& Potter JW (1968) Comparative studies of the rat and pigeon liver fatty acid synthetases. Arch Biochem Biophys 126, 141-154.

25. Kumar S, Dorsey JA, Muesing RA, et al. (1970) Comparative studies of the pigeon liver fatty acid synthetase complex and its subunits. Kinetics of partial reactions and the number of binding sites for acetyl and malonyl groups. $J$ Biol Chem 245, 4732-4744.

26. Carey EM \& Dils R (1970) Fatty acid biosynthesis. V. Purification and characterisation of fatty acid synthetase from lactatingrabbit mammary gland. Biochem Biophys Acta 210, 371-387.

27. Guglielmo CG, Norbert NH, Hochachka PW, et al. (2002) Seasonal dynamics of flight muscle fatty acid binding protein and catabolic enzymes in a migratory shorebird. Am J Physiol Regul Integr Comp Physiol 282, R1405-R1413.

28. Davidson AL \& Arion WJ (1987) Factors underlying significant underestimations of glucokinase activity in crude liver extracts: physiological implications of higher cellular activity. Arch Biochem Biophys 253, 156-167.

29. Lange AJ, Arion WJ, Burchell A, et al. (1986) Aluminum ions are required for stabilization and inhibition of hepatic microsomal glucose-6-phoshatase by sodium fluoride. J Biol Chem 261, 101-107.

30. Benjamini Y \& Hochberg Y (1995) Controlling the false discovery rate: a practical and powerful approach to multiple testing. J R Stat Soc B 57, 289-300.

31. Li C (2006) Genetics and regulation of angiopoietin-like proteins 3 and 4. Curr Opin Lipidol 17, 152-156.

32. Köster A, Chao YB, Mosior M, et al. (2005) Transgenic angiopoietin-like (angptl)4 overexpression and targeted disruption of angptl4 and angptl3: regulation of triglyceride metabolism. Endocrinology 146, 4943-4950.

33. DeFronzo RA (1999) Pharmacologic therapy for type 2 diabetes mellitus. Ann Intern Med 17, 281-303. 
34. Gastaldelli A, Cusi K, Pettiti M, et al. (2007) Relationship between hepatic/visceral fat and hepatic insulin resistance in nondiabetic and type 2 diabetic subjects. Gastroenterology 133, 496-506.

35. Hundal RS, Krssak M, Dufour S, et al. (2000) Mechanism by which metformin reduces glucose production in type 2 diabetes. Diabetes 49, 2063-2069.

36. Hofmann C, Lorenz K, Braithwaite SS, et al. (1994) Altered gene expression for tumor necrosis factor- $\alpha$ and its receptors during drug and dietary modulation of insulin resistance. Endocrinology 134, 264-270
37. Suganami T, Nishida J \& Ogawa Y (2005) A paracrine loop between adipocytes and macrophages aggravates inflammatory changes: role of free fatty acids and tumor necrosis factor $\alpha$. Arterioscler Thromb Vasc Biol 25, 2062-2068.

38. Reaven GM (2005) The insulin resistance syndrome: definition and dietary approaches to treatment. Annu Rev Nutr 25, 391-406

39. Hotamisligil GS, Shargill NS \& Spiegelman BM (1993) Adipose expression of tumor necrosis factor- $\alpha$ : direct role in obesity-linked insulin resistance. Science 259, 87-91. 